\title{
Gold Leaf Murano Glass Piastras' Performance in the Trencadís Catalan Modernism Mosaic: Recognition of Primary Alteration Patterns
}

\author{
Héctor Y. Orozco Camargo ${ }^{1}$ and Joan Ll. Zamora i Mestre ${ }^{2}$ \\ ${ }^{1}$ Master's Degree in Advanced Studies in Architecture-Barcelona (MBArch), Universitat Politècnica \\ de Catalunya-BarcelonaTECH, ETSAB, Av. Diagonal, 649, 08028-Barcelona, Spain, Arq- \\ HO@hotmail.com \\ ${ }^{2}$ Laboratori d'Innovació i Tecnologia de l'Arquitectura (LiTA), Universitat Politècnica de Catalunya \\ (UPC) - BarcelonaTECH, Pere Serra, 1-15, 08173-Sant Cugat del Vallès, Catalunya, Spain, \\ joan.1luis.zamora@upc.edu
}

\begin{abstract}
Gold leaf Murano glass is a unique product that over the centuries, especially during Byzantine period, has been used as facing forming big flat or curved mosaics that result in an architecture full of light and symbolism. This product is presented in a format of squared piastras with the same approximate dimensions that the gold leaves ones have $(8 \times 8 \mathrm{~cm})$. Piastras are cut in smaller squares $(1-1,5 \mathrm{~cm})$ in order to obtain the tiles that form mosaic's cladding. This cladding technique was incorporated during Catalan Modernism. Through this technique, beautiful pieces of tesseras of gold leaf Murano glass combined with others of opaline glass. In order to overcome the artistic challenges from this architectural movement, new mosaics were placed outdoors in order to shine by the incident sun beams and the square tiles were replaced by irregular tiles that form polygonal meshes capable of coating double curvature surfaces with great elegance. This location and prolonged exposure to the weather cause, over time, a deteriorated appearance, despite being composed of great resistant materials such as gold and glass. Studies oriented to know the phenomenology of this deterioration are being carried out and its impact on the expected durability of this coating. Being a handmade product and completely manual execution, the first studies have aimed to identify the primary anomalies that are originally generated in the different layers of this product at the time of manufacture, transport and handling. Knowing these primary anomalies must allow to prevent their occurrence and reduce their incidence in the manifestation of so-called secondary anomalies. All this in order to prolong the useful life of this appreciated architectural cladding.
\end{abstract}

Keywords: Brightness, Mosaic, Modernism, Trencadis, Gold leaf Murano Glass, Alteration Patterns.

\section{Introduction}

Gold Leaf Murano glass consists of two external layers of different thickness and different glasses and a thin inner layer of gold leaf inserted between both. The main purpose of this product is to provide a glazed surface with the maximum brightness, colouring and texture. These features are given by the gold leaf itself. The two layers of glass provide to the gold leaf protection and transparency.

Gold is a ductile and soft material that does not corrode when it contacts with air. Gold it is not reactive not toxic. In contrast, it is an excellent reflector of infrared radiation. It is also a good heat absorber and it has a great capacity to reflect light. Within its chemical peculiarities, it should be mentioned that gold is easily lacklustre by sulphur (lost of brightness), attacked by 
chlorin and for cyanide solutions in the presence of oxygen and insoluble in acids. Since gold leaves are a handmade material, occasionally, their alloys are made with other metals to reduce its cost and to obtain nuance variations in its colour appearance. Currently, there are different active gold leaf Murano glass producers. This research has been carried out on piastras with dimensions of $8 \times 8 \mathrm{~cm}$, and with an approximate thickness of $6 \mathrm{~mm}$, without any treatment or alteration, as delivered by the distributor. Samples of gold leaf Murano glass consist of a first layer of transparent common glass of $6 \mathrm{~mm}$ of thickness approximately (face A) + a gold leaf layer with a thickness of between 0,1 and $0,001 \mu \mathrm{m}$ approximately + a transparent blown glass with a thickness between $0,2 \mathrm{~mm}$ and $0,5 \mathrm{~mm}$ (face B), which is shown in the image 1 .

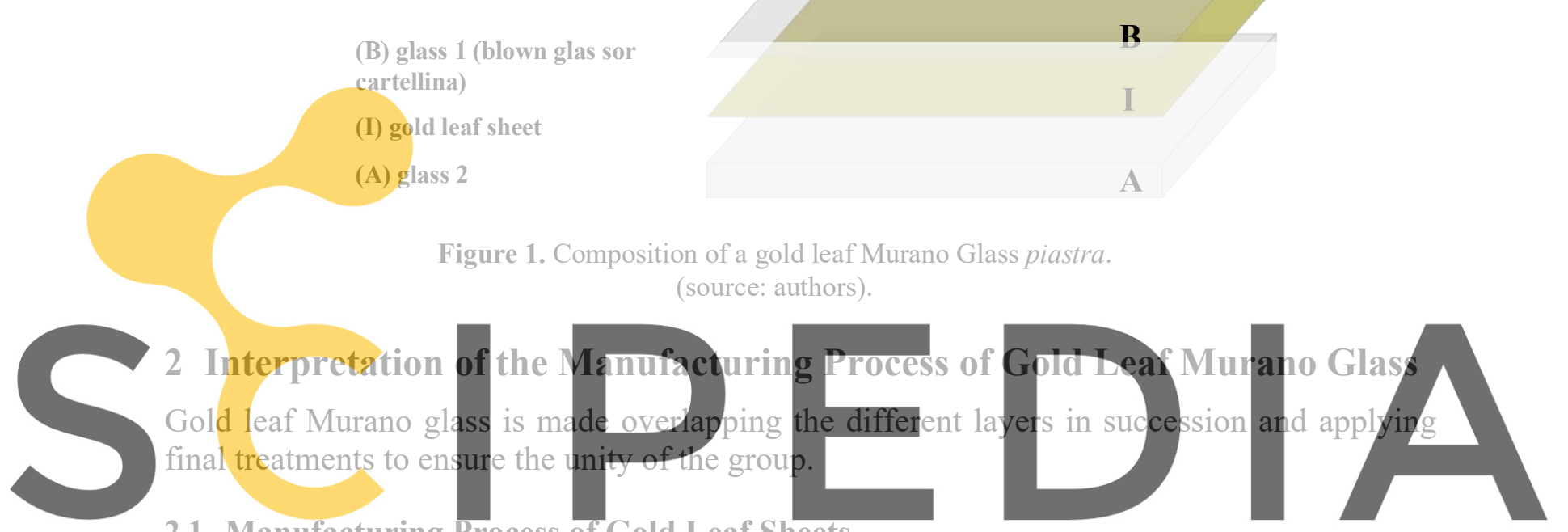

2.1 Manufacturing Process of Gold Leaf Sheets

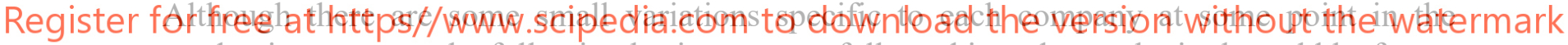
production process, the following basic steps are followed in order to obtain the gold leaf:

1. Heavy: gold from other remains is weighed.

2. Melting: by melting, a ingot of approximately $1 \mathrm{~cm}$ thick is obtained.

3. Laminate $\mathrm{I}$ : it is the first forming that is done by inserting the ingot between two horizontal rollers. This process is done very slowly so as not to lose gold's malleability.

4. Measurement and cut: a measure is made with a compass in order to know where to cut the tapes that have already left the laminate. After this, the various plates are put together to continue with the next step.

5. Laminate II: through this second lamination by other rollers flat pieces of $4 \times 4 \mathrm{~cm}$ are obtained.

6. Counterbalancing and cut: previously laminated the gold leaf sheets are counterbalanced one on the other, in the middle of it, is bent perpendicularly with a wooden dowel and cut in half. They are then counterbalanced and cut again, resulting in pieces of $2 \mathrm{~cm} \times 2 \mathrm{~cm}$.

From these pieces obtained from $2 \mathrm{~cm} \times 2 \mathrm{~cm}$, hammering processes are applied with different levels of force to progressively reduce the thickness of the sheets.

7. Step for devastate: The first step in achieving this part of the process is to reduce as much as possible the humidity of the devastating device that will receive the gold, a process called 
the "preparing". Followed by this, the gold is loaded into the devastating and then the smoothing process, which consists of constantly hitting the sheets while they are spinning. They are then cut again into $4 \mathrm{~cm} \times 4 \mathrm{~cm}$ sheets.

8. Movement of the brazed: the same steps of the previous process are performed again with the aim of further reducing the thickness.

9. Movement of the mould: it is the final stage of hammering, in which it is sought that the centre of the surface of the bread and the rest perimeter have the same thickness and not present differential defects.

10. Transfer into books: it is the last step and consists of passing gold leaf sheets to white silk paper books to preserve it from humidity. The usual final measurement of the surface of the sheets is $8 \mathrm{~cm} \times 8 \mathrm{~cm}$.

During the manufacturing process of the gold leaf, the gold leaf may turn sour. This can happen repeatedly. In that case, the gold loses malleability, so it has to be cooked again and a resurrected is generated in which a greater molecular cohesion is created by which the gold increases its density.

\subsection{Manufacturing Process for Murano Gold Leaf Glass}

The primary anomalies can occur in any of the different processes that are carried out for the manufacture, transport and handling of the product so it is important to know the development of each of the phases.

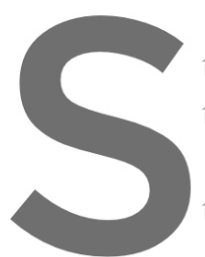

1. The production

transparent blown glass then cut into square seg

2. The gold leaf is

these glass segments

3. The next step is the
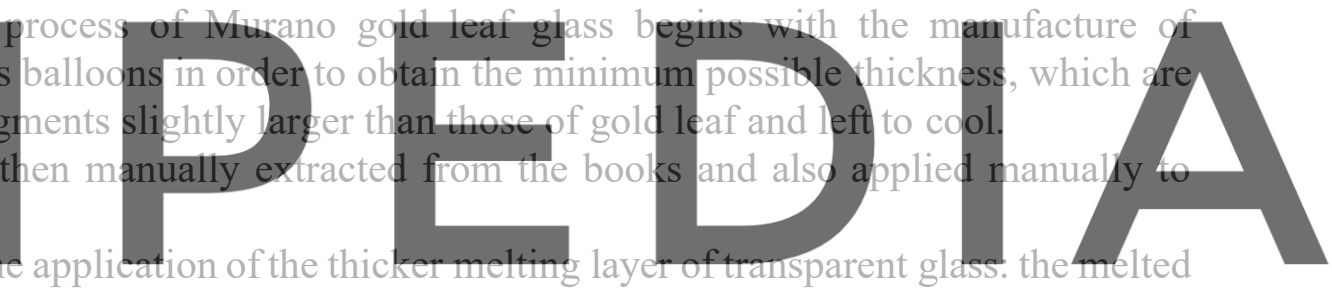

glass is poured onto the exposed face of the gold leaf and reheated to the gold leaf and the fine

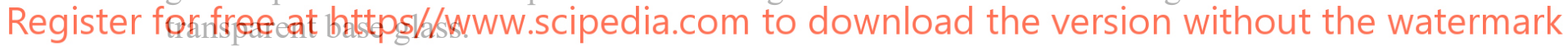

4. While the assembly is malleable, it is passed successively through several rollers to reduce the thickness to the desired thickness (approximately $5.95 \mathrm{~mm}$ ) and the flat shape.

5. The piastras thus formed are raised with pliers and rotated to allow the best integration of the different layers.

6. Once the sheets of gold leaf are fully protected by both glasses, the whole is taken to the oven with the aim of sealing and definitively joining the different layers.

7. The parts removed from the furnace are again passed through the rollers because, having been subjected again to high temperatures, their thickness may have varied.

8. During the slow cooling, but even if the set is malleable, the pieces are cut again with the measurements of the format of the gold leaf $(8 \mathrm{~cm} \times 8 \mathrm{~cm})$. 
The product is stored until transport, the truck being the most common means of transport. For this purpose, the pieces are grouped and packed in honeycomb plastic film to avoid any possible external friction and are deposited inside boxes

\section{Research Methodology}

Since manufacturing is done by hand, this results in visually noticeable variations within the same batch of product; is why this study has been carried out using a comparative methodology of different samples in order to identify the most frequent anomalies. Similarly, this product is not covered by any regularity and its characteristics must be assessed by assimilation with other standards.

\subsection{Scanning by Flat Scanner}

Firstly, a cursory inspection of the parts was carried out, the parts were carefully washed and numbered. The parts have subsequently been digitized on both sides by the use of the flat scanner, obtaining digital images in .jpg. The use of the flat scanner model EPSON GT-15000 has proyed to be the most efficient way of keeping a record and a detailed survey of all the pieces studied. The stored digital images have not had any kind of digital processing or subsequent manipulation.

The observation of this survey has confirmed that Murano gold leaf glass is a translucent and heterogeneous product, characterized by the light and shadow contrasts generated by the

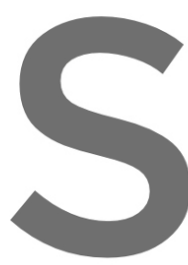
variation of the surfade

3.2 Visuall-Instrument
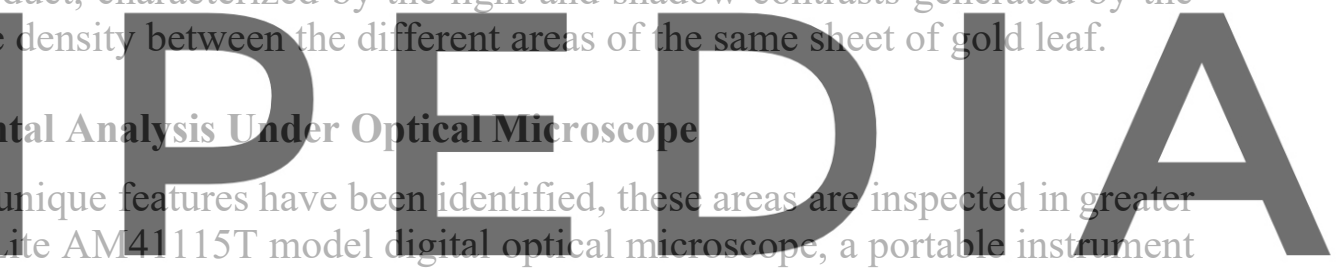

that allows in a very simple way to make a more detailed enlargement of the structure of these

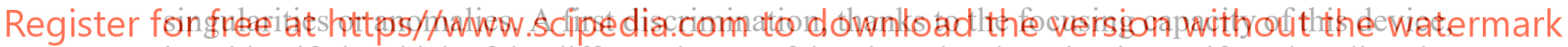
is to identify in which of the different layers of the piece the alteration is manifested. Indirectly, the position of the anomaly may indicate when the production process occurred.

For the development of this study, three types of zoom have been carried out, depending on the face and the approach, in order to determine in which layer of the sample the anomaly is located; if they are on the inside face of the glass (a)on the sheet of gold leaf (b) or on the outer faces of protective glass (c):

- First, a 19X zoom was performed on side B (the smallest glass thickness) in order to observe the anomalies between layers.

- The same procedure is carried out on side A, but this time a 20X zoom is used as a thicker glass is being analysed and, Therefore, the focus for observing the golden material is at a greater distance from the surface.

- The last increase is made to $160 \mathrm{X}$ on both sides since with this increase it is interesting to analyse what is happening on the surface of the glasses.

Finally, these identified anomalies have been compiled in different groups, according to the layers in which they manifest: 
- Group 1, anomalies located on the inside face of the glass (a) or on the sheet of gold leaf (b) and

- Group 2, anomalies located on the outer faces of the protective glass (c).
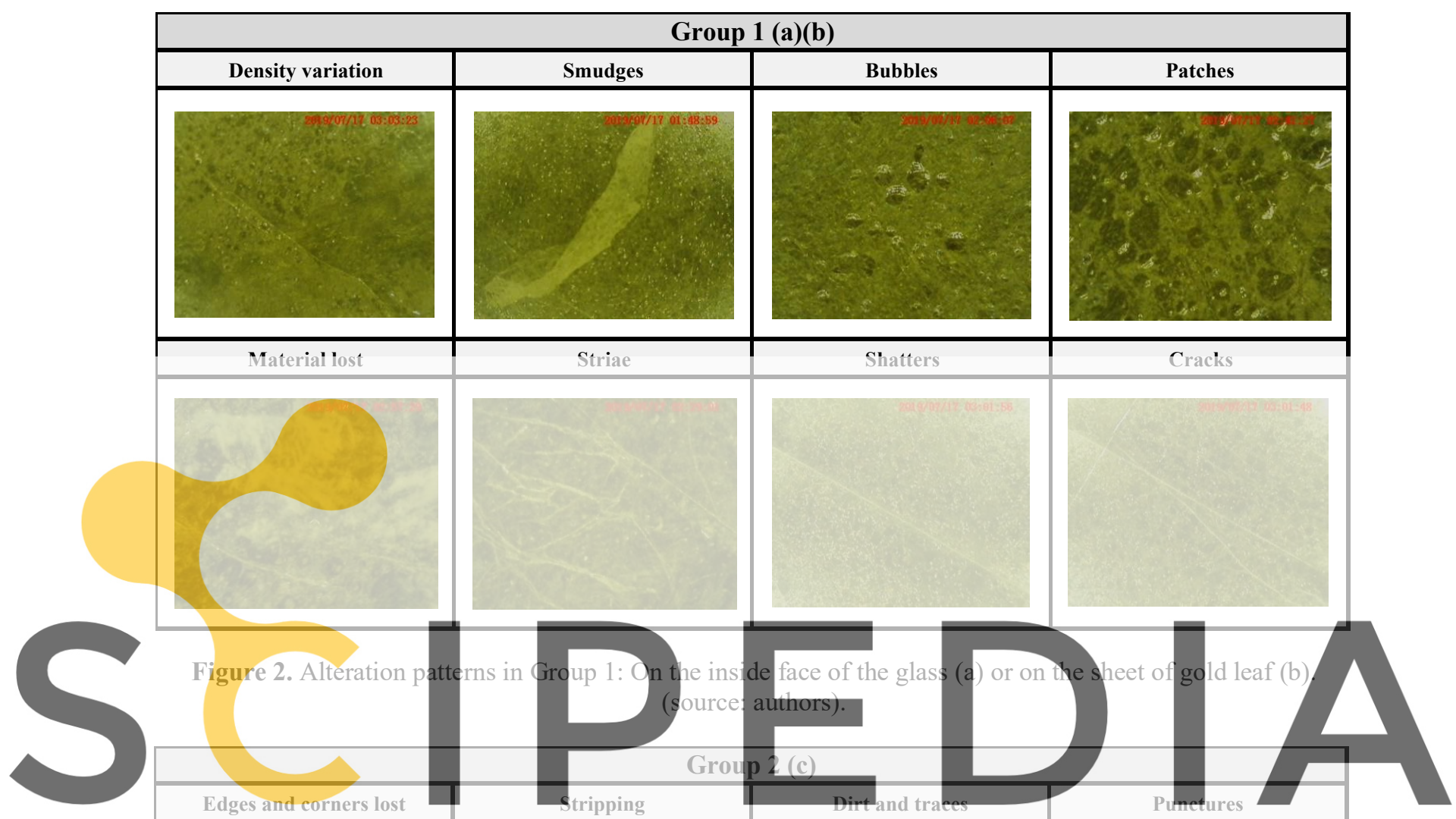

Register for free at https//www.scipedia.com to download the version without the watermark
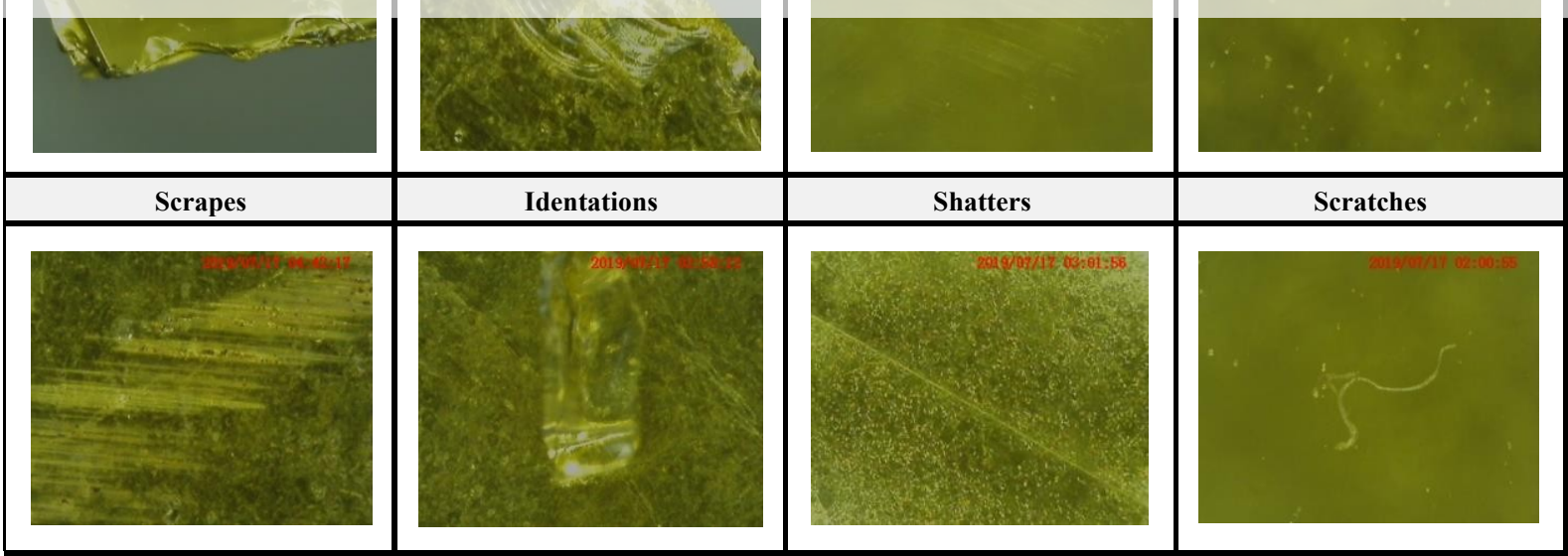

Figure 3. Alteration patterns in Group 2: On the outer faces of the protective glass (c). (source: authors). 


\subsection{Properties of Murano Glass Gold Leaf in Laboratory}

In order to assess the durability of this product in a standardised way, a series of laboratory tests have been carried out following the UNE-EN ISO 10545 regulation for ceramic tiles; This decision was taken on the grounds that ceramic tiles are the alternative material most commonly used in the Catalan Modernism trencadis exterior cladding.

The tests that have been carried out are: determination of water absorption, open porosity, relative density and bulk density; determination of resistance to bending and breaking load; determination of chemical resistance; Determination of stain resistance; Determination of thermal shock resistance; Determination of surface abrasion resistance of enamelled tiles; Determination of scratch hardness; Determination of linear thermal expansion and Determination of freezing resistance. The 9 tests were carried out by a company specialising in this field.

- After the test on five piastras for the determination of water absorption, open porosity, relative and apparent density was obtained as a result of the mean values that the absorption of water from gold leaf Murano glass is $0.01 \%$, the apparent porosity of $0.02 \%$ and both the relative and apparent density of $2,51 \mathrm{~g} / \mathrm{cm} 3$, the common density of a glass.

- In order to determine the bending strength and the breaking load, seven samples were submitted with an average breaking strength of $2262 \mathrm{~N}$, a resistance similar to that of rustic sandstone. While the maximum bending strength is $84.5 \mathrm{~N} / \mathrm{mm} 2$, a value very close to the strength of a tempered glass.

- The test for chennicicing

effects and therefore

salts. Similarly, resistance

class: HA and LA respectively.

- Three groups of 5 pring

that the resistance of the product to stains is the
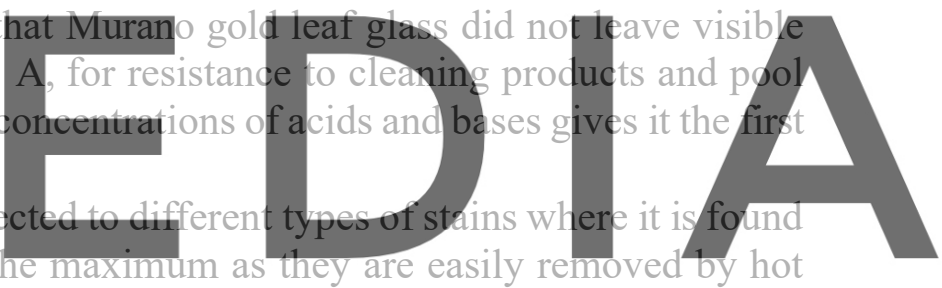
water.

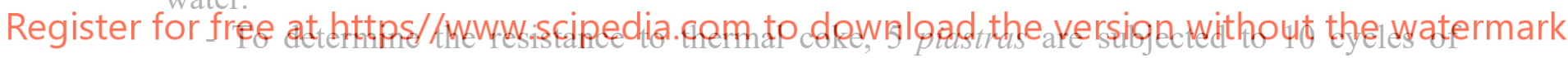
temperature variation between $15^{\circ} \mathrm{C}$ and $145^{\circ} \mathrm{C}$ by immersion. From the second cycle the product begins to crack and aiready in the third, pieces begin to fall off. The Mirano glass of gold leaf having a metallic element between its layers, possesses a cohesion that helps to keep the whole together.

- The surface abrasion resistance test is evaluated by the PEI method (wet abrasion method) which measures the surface wear resistance of tiles and is classified in 5 degrees, where class 5 corresponds to the highest resistance. After the tests carried out on the samples, a result is given where the product corresponds to class 2 where the visible effects start to appear from 600 revolutions. 
- For the determination of scratch resistance, the Mohs scale is used which, although already out of print, is not yet available for the determination of this type of test. After testing according to the Mohs scale, gold leaf Murano glass belongs to hardness 4, that is to the mineral: fluorite. A result far below the classification of glass strength.

- The results of the test to determine the resistance to linear thermal expansion, conclude with a variation of the expansion of the material with respect to the origin of $7,4 \times 10-6 /{ }^{\circ} \mathrm{C}$ in longitudinal direction and $7,6 \times 10-6 /{ }^{\circ} \mathrm{C}$ in a transverse direction, a result that is not significant.

- Finally. The test carried out to determine the resistance to frost results in $0 \%$ absorption and no defects.

\section{Conclusions}

- From the moment of its production, gold leaf Murano glass already presents substantial anomalies that can alter its future behaviour and durability.
The manufacture and treatment of this product in its early stages should be more careful to reduce the risk of the occurrence of primary abnormalities which may be a risk factor for accelerating the occurrence of secondary abnormalities.

\section{The control of primary anomalies should not be to the detriment of the visual markings} of this product.

The first tests carried out in the laboratory indicate the appropriate quality of the glass and confirm some initial forecasts such as its weakness in the face of thermal shock or
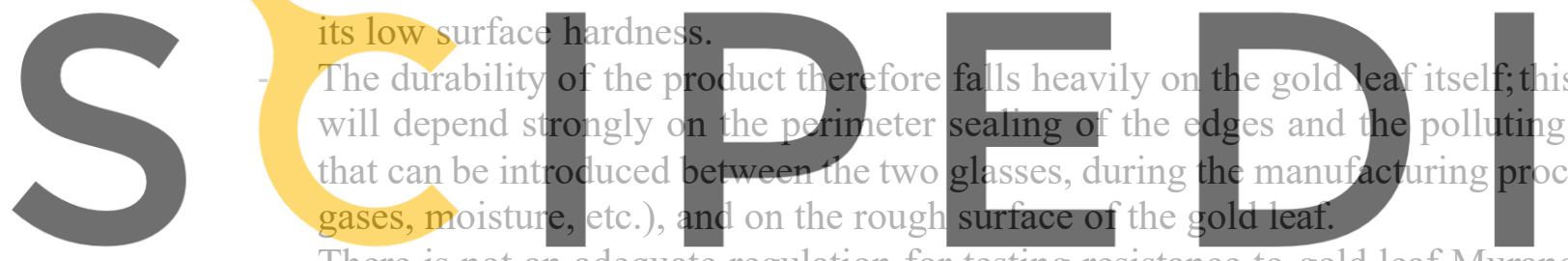

There is not an adequate regulation for testing resistance to gold leaf Murano glass as

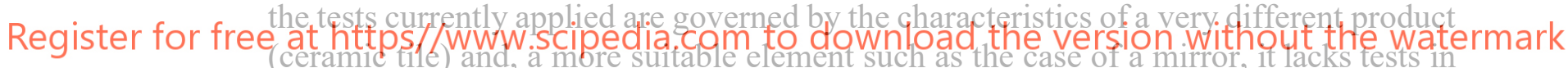

\section{the regulation that applies to it.}

The evaluation of the durability of this product according to the standard product of the flat glass industry, which is the mirror, has been pending for future research. The standard UNE-EN 1036 Silver-coated glass mirrors for internal use, even if it is confined to indoor situations, includes some environmental actions such as humidity and temperature in bathrooms. The conventional mirrors are flat, transparent, colourless, sodochalcium silicate glasses with parallel and polished faces, the rear face of which is covered with a sheltered silver reflecting reservoir, all this with a thickness between 2 and $10 \mathrm{~mm}$ allowed.

- It has been pending for future studies to evaluate the integrity of the whole when mechanical fractionation of the piastras is carried out by shear to obtain the irregular polygonal tesserae typical of the trencadis: in the case of glass of different composition and thickness, the mechanical fracture may give rise to weaknesses which leave the gold leaf unprotected from the external environment. 


\section{ORCID}

Héctor Orozco: https://orcid.org/0000-0002-7436-2843

Joan Ll. Zamora: https://orcid.org/0000-0002-7705-6171

\section{References}

AENOR. (2009). Norma española. UNE-EN 1036. Vidrio para la edificación. Espejos de vidrio recubiertos de plata para uso interno (in Spanish). Madrid, Spain

AENOR. (2015). Norma española. UNE-EN ISO 10545. Baldosas cerámicas (in Spanish). Madrid, Spain

Dal Bianco, B. and Russo, U. (2012). Basilica of San Marco (Venice, Italy/Byzantine period): Nondestructive investigation on the glass Mosaic Tesserae. Journal of Non-Crystalline solids, 358(12-13), 1629. https://doi.org/10.1016/j.jnoncrysol.2011.10.006

De la Colina Tejeda, L. (2001). El oro en hoja: aplicación y tratamiento sobre soportes móviles tradicionales, muro $y$ resinas (in Spanish). PhD Thesis, Universidad Complutense de Madrid. Spain. http://eprints.ucm.es/7082/

Neri, E., Verità, M., Biron, I. and Guerra, M.F. (2016). Glass and gold: Analyses of 4th-12th centuries Levantine mosaic tesserae. A contribution to technological and chronological knowledge. Journal of Archaeological Science, 70, 158-171, https://doi.org/10.1016/j.jas.2016.05.003

Römich, H. (1999). The Conservation of Glass and Ceramics. Historical glass and its interaction with the environment. James \& James, Londres, Inglaterra, Norman H. Tennent Ed. ISBN 1-873936-18-4

Verità, M. (2006). Tessere vitree a foglia d'oro nei mosaici di Aquilea (in Italian). Quaderni Friulani di Archeologia XVI/2006, Murano-Venecia, Italia: Stazione Sperimentale del Vetro.

Verità, M., James, L., Freestone, I., Henderson, J., Nenna, M.D. and Shibille, N. (2009). Glossary of Mosaic Glass Terms. Centre for Byzantine Cultural History 2009, Brighton, Inglaterra: University of Sussex.

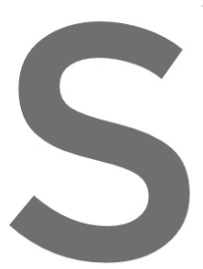

Whitehouse, D. (2006) Glassmaking. Nueva
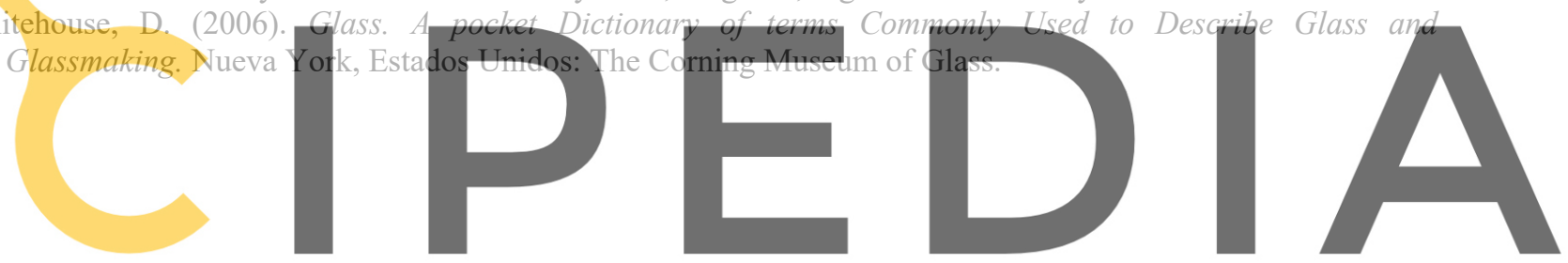

Register for free at https//www.scipedia.com to download the version without the watermark 